\title{
Cooking with Karen: the New Diva of EM Culinary Cuisine. The Use of Microwave Technology in a Pharmaceutical EM Laboratory
}

\author{
Karen A. Killary, and Gregory J. Argentieri
}

Novartis Pharmaceuticals Corporation, Preclinical Safety, Electron Microscopy Laboratory, One Health Plaza, East Hanover, NJ 07936

Remember the first time you popped that hot dog into your new home microwave oven and cooked it in only one minute? A new era of food preparation was born. Adapting this common household appliance for everyday use in a pharmaceutical laboratory is revolutionary. Not since the introduction of the automatic tissue processor has there been such innovation in the world of transmission electron microscopy tissue processing!

Microwave (MW) assisted processing offers a new recipe for success using existing ingredients and new efficient methods. By combining conventional electron microscopy (EM) embedding with MW processing, samples can be collected at necropsy in the morning, processed in the afternoon, and embedded by day's end. The MW assisted processing procedures of Rick Giberson (Ted Pella, Inc) and others [1-3] can be adapted to the pharmaceutical EM laboratory. Routine preparation of multiple samples is as simple as following a recipe - short and sweet!

Must Have "Appliances"

- $\quad$ PELCO BioWave ${ }^{\mathrm{TM}}$ with variable wattage, (model 34700)- eliminates 'cooked' tissue.

- PELCO ColdSpot ${ }^{\mathrm{TM}}$ - reduces MW hot spots.

- MW vacuum chamber (PELCO 3435)- speeds up resin infiltration to just minutes.

- PELCO Prep-Eze ${ }^{\mathrm{TM}}$ specimen holders- each holds six samples; can use more than one at a time.

Secret to Success Tips

- Prepare all ingredients, reagents, chemicals and supplies in advance. Microwave processing is fast; the time between steps is too short to use for prep time.

- Determine the quantities of reagents actually used per sample batch. Make recipe batch cards for quick reference. This saves time and reduces waste.

- Use the fixation chart and processing schedule on the next page as guides. Plug fixation time sequence into processing schedule. Check off each step as you go, and take notes to improve your process for the future runs.

The manufacturer's instructions, technical notes, scientific papers, and advice were invaluable in setting up a recipe for success in this pharmaceutical environment [4].

References

[1] Ted Pella Inc, Microwave-assisted Rapid Processing Protocol for Electron Microscopy, 9/1997.

[2] RT Giberson, et al., J Vet Diagn Invest, 9:61-67, 1997.

[3] RT Giberson \& RS Demaree Jr., Microwave Techniques and Protocols, Humana Press, Inc 2001.

[4] PELCO Technical Notes, A New Era in Microwave Processing, MWI TN 10/11/01. 


\section{Fixation Chart}

\begin{tabular}{|c|c|}
\hline $\begin{array}{c}\text { Fixative } \\
\left(\text { cool }<20^{\circ} \mathrm{C}\right) \\
\text { Temp restriction }<37^{\circ} \mathrm{C}\end{array}$ & $\begin{array}{c}\text { Routine tissues with } \\
\text { vacuum on }\end{array}$ \\
\hline $\begin{array}{l}\text { Mod. Karnovsky's or } \\
\text { paraformaldehyde } \\
\text { containing fixatives }\end{array}$ & $\begin{array}{l}1 \text { min off (HOLD), } \\
70-250 \mathrm{~W} 40-80 \mathrm{~s} \text { on, } \\
3 \text { mins off, } \\
350-450 \mathrm{~W} 40 \mathrm{~s} \text { on }\end{array}$ \\
\hline Glutaraldehyde & $\begin{array}{l}1 \text { min off, } \\
70-250 \mathrm{~W} 40-80 \text { s on, } \\
3 \text { mins off }\end{array}$ \\
\hline $\begin{array}{l}\text { Osmium tetroxide } \\
\text { (as } 1^{\circ} \text { or } 2^{\circ} \text { fixative) }\end{array}$ & $\begin{array}{l}1 \text { min off, } \\
250 \mathrm{~W} 40-80 \text { s on, } \\
3 \text { mins off }\end{array}$ \\
\hline \multicolumn{2}{|c|}{$\begin{array}{l}\text { Repeat indicated time sequence } 2-6 \mathrm{X} \text { for difficult } \\
\text { to fix tissues. } \quad \mathrm{W}=\text { watts }\end{array}$} \\
\hline
\end{tabular}

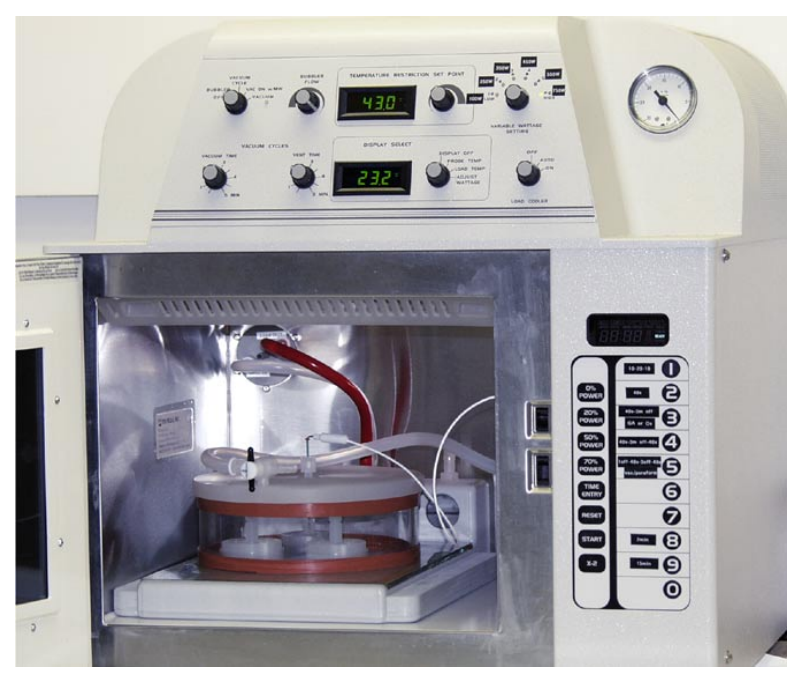

\section{Suggested Microwave Tissue Processing Checklist Project}

Species:

Sample(s):

Compound:

\author{
$1^{\circ}$ Fixative: \\ Buffer: \\ $2^{\circ}$ Fixative:
}

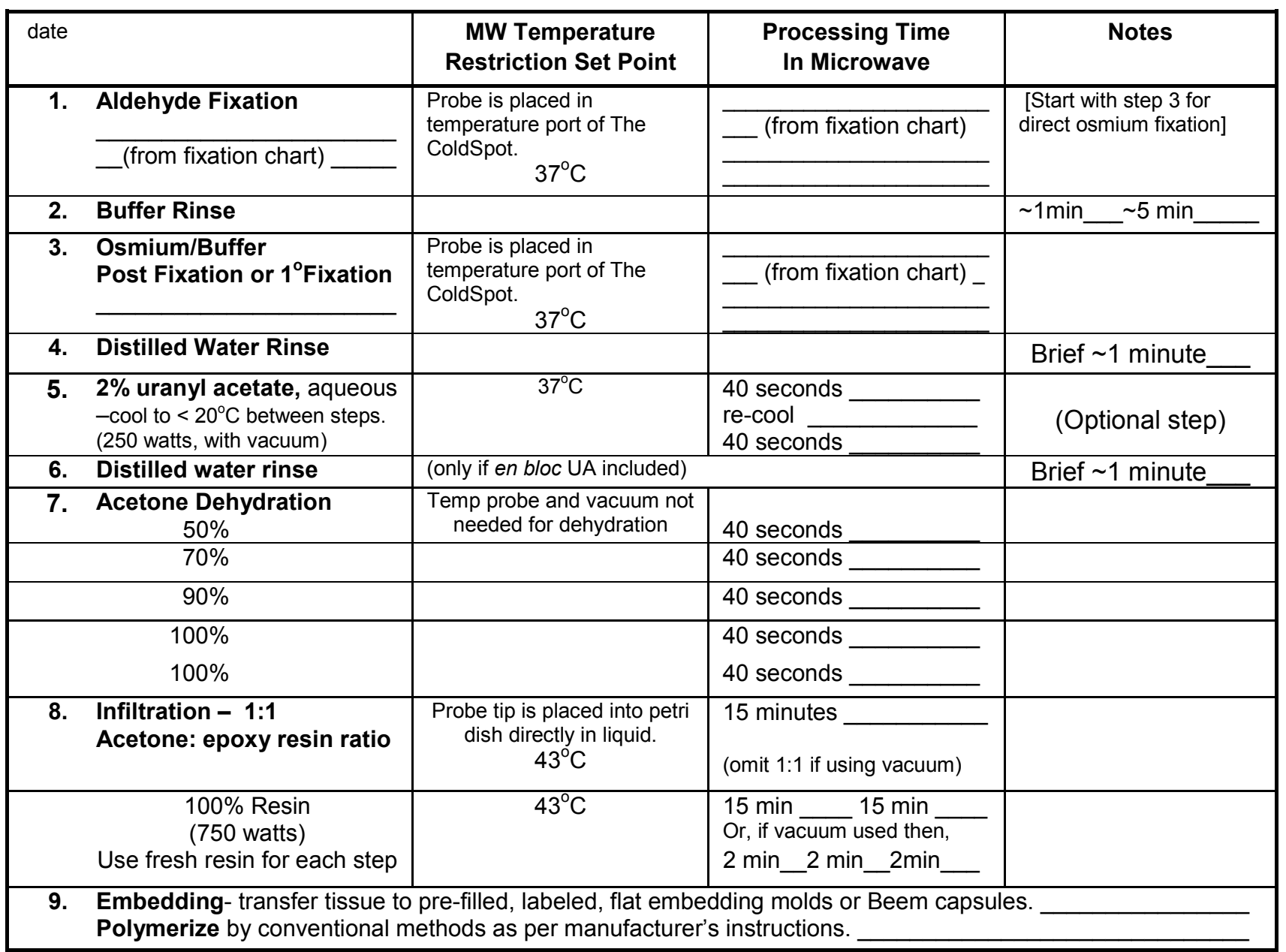

